\title{
Intraarterial Hepatic SPECT/CT Imaging Using 99m Tc-Macroaggregated Albumin in Preparation for Radioembolization
}

\author{
Vanessa L. Gates ${ }^{1}$, Nimarta Singh ${ }^{2}$, Robert J. Lewandowski², Stewart Spies ${ }^{1}$, and Riad Salem ${ }^{2}$ \\ ${ }^{I}$ Section of Interventional Radiology, Department of Radiology, Northwestern Memorial Hospital, Robert H. Lurie Comprehensive \\ Cancer Center, Chicago, Illinois; and ${ }^{2}$ Division of Hematology and Oncology, Department of Medicine, Robert H. Lurie \\ Comprehensive Cancer Center, Northwestern University, Chicago, Illinois
}

\begin{abstract}
Current standard practice for radioembolization treatment planning makes use of nuclear medicine imaging (NMI) of ${ }^{99 \mathrm{~m} T c-m a c r o a g-}$ gregated albumin ( ${ }^{99 m}$ Tc-MAA) arterial distributions for the assessment of lung shunting and extrahepatic uptake. Our aim was to retrospectively compare NMI with mapping angiography in the de-

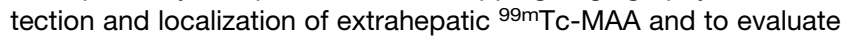
the typical and atypical findings of NMI in association with catheter placement. Methods: One hundred seventy-four patients underwent diagnostic angiography in preparation for radioembolization. 99mTc-MAA was administered to the liver via a microcatheter positioned in the desired hepatic artery. Planar scintigraphy imaging followed by SPECT/CT imaging was obtained within $2 \mathrm{~h}$. All images were reviewed for hepatic and extrahepatic 99mTc-MAA deposition and compared with the mapping angiogram. Results: Intrahepatic lobe shunting was present on NMI in only $2.9 \%$ of the cases but was present in $62.5 \%$ of the patients with portal vein thrombosis. Extrahepatic distributions included lungs (100\%), the gallbladder $(49 \%)$ if present, and locations involving hepaticoenteric arterial anatomy recognized on angiograms (16\%). Free pertechnetate was identified on $38 \%$ of the nuclear medicine images. Three percent of nuclear medicine images showed alternative findings such as a thyroid nodule or metallic artifact. Conclusion: Patients being considered for radioembolization should undergo both angiography and scintigraphy for the assessment of hepaticoenteric arterial anatomy, hepatopulmonary shunting, and appropriate dosimetry considerations. Knowledge of the expected distribution of ${ }^{99 m T c-M A A}$ with normal variants and potential nontarget delivery to adjacent structures is critical in improving clinical outcomes.
\end{abstract}

Key Words: liver neoplasms; radiotherapy; radioembolization; ${ }^{99 \mathrm{~m} T c-m a c r o a g g r e g a t e d ~ a l b u m i n ; ~ S P E C T / C T ; ~}{ }^{90} Y$-microspheres

J Nucl Med 2015; 56:1157-1162

DOI: 10.2967/jnumed.114.153346

C urrently, nuclear medicine imaging (NMI) of ${ }^{99 \mathrm{~m}} \mathrm{Tc}$-labeled macroaggregated albumin ( ${ }^{99 \mathrm{~m}} \mathrm{Tc}-\mathrm{MAA}$ ) is performed routinely before radioembolization for the assessment of lung shunting

\footnotetext{
Received Dec. 31, 2014; revision accepted Jun. 9, 2015.

For correspondence or reprints contact: Riad Salem, Interventional Oncology, Section of Interventional Radiology, Department of Radiology, 676 N. St. Clair, Suite 800, Chicago, Illinois 60611.

E-mail: r-salem@northwestern.edu

Published online Jun. 18, 2015.

COPYRIGHT (c) 2015 by the Society of Nuclear Medicine and Molecular Imaging, Inc.
}

and extrahepatic uptake. NMI is widely recognized to be important for minimizing the risk of potentially debilitating adverse events such as radiation-induced pneumonitis or radiation gastritis/duodenitis after radioembolization using ${ }^{90} \mathrm{Y}$-microspheres for inoperable hepatic tumors $(1,2)$. The seminal work in a canine liver model demonstrating the safety and feasibility of using ${ }^{90} \mathrm{Y}$-microsphere therapy for hepatic malignancies was reported in the late 1980s. Human studies of ${ }^{90} \mathrm{Y}$-microsphere therapy in liver applications followed from the late 1980s through the 1990s. These investigations established the safety of ${ }^{90} \mathrm{Y}$ for intrahepatic applications and the optimal dosimetry for tumor radiation kill, while minimizing exposure to normal liver tissue (3-8).

Given the similarities in sizes of ${ }^{90} \mathrm{Y}$-microspheres $(20-40 \mu \mathrm{m})$ and ${ }^{99 \mathrm{~m} T c-M A A}(20-50 \mu \mathrm{m})$, the pattern of ${ }^{99 \mathrm{~m} T c-M A A}$ deposition as determined from a high-resolution SPECT/CT acquisition serves as a surrogate to demonstrate how ${ }^{90} \mathrm{Y}$-microspheres will localize during treatment. Radioembolization has evolved for the palliative treatment of patients with primary and secondary malignancies. Meticulous pretreatment planning with angiography and ${ }^{99 m}$ Tc-MAA scintigraphy allows for a low-toxicity profile, increased response rates, and low incidence of posttreatment complications for patients (9). The purpose of this paper was to demonstrate the typical and atypical findings of ${ }^{99 \mathrm{~m}} \mathrm{Tc}-\mathrm{MAA}$ distribution obtained as part of pretherapeutic planning for radioembolization with ${ }^{90} \mathrm{Y}$-microspheres.

\section{MATERIALS AND METHODS}

\section{Patients}

This research was completed with the approval of the Northwestern University Investigational Review Board, all subjects signed a written informed consent form, and procedures followed were in accordance with the ethical standards of the Helsinki Declaration of 1975, as revised in 2008. Between March 2009 and September 2010, 174 patients underwent pretreatment diagnostic angiography with ${ }^{99 m}$ Tc-MAA administered via a microcatheter positioned in a hepatic artery (placed at the discretion of the attending interventional radiologist). Subsequently, all patients were treated with ${ }^{90}$ Y-glass microspheres (TheraSphere; BTG International). Technical details for radioembolization have been discussed in detail elsewhere $(10,11)$. Ninety-one patients were being treated for metastatic disease of the liver (colorectal cancer [40], neuroendocrine disease [20], cholangiocarcinoma [15], and miscellaneous origin [16]). Eighty-three patients were being treated for primary hepatocellular carcinoma (HCC).

\section{Diagnostic Arterial Imaging}

As part of the routine diagnostic work-up completed 1-2 wk before radioembolization treatment, all patients were administered 74-148 MBq 
of ${ }^{99 m}$ Tc-MAA via a microcatheter positioned in an hepatic artery. Static scintigraphy imaging followed by SPECT/CT imaging was initiated within $2 \mathrm{~h}$ after the administration of ${ }^{99 \mathrm{~m} T c-M A A}$. For planar imaging, the patient was positioned supine under the $\gamma$ camera, and 4 images were acquired: anterior and posterior images of the abdomen and anterior and posterior images of the thorax. Each image was acquired for $5 \mathrm{~min}$ in a $256 \times 256$ matrix without scatter correction. A region of interest to determine counts was drawn around the liver activity, each individual lung activity, a background region below the liver, and background regions on the lateral side of each lung. The cardiac pool was not included in the lung count estimates. The liver-to-lung shunt was calculated as the geometric mean of the net counts within the lungs divided by the sum of the geometric mean of the net liver counts and the net lungs counts.

Arterial distribution of the particles was quantified from SPECT/ CT-fused images that were obtained on the Siemens Symbia T2 (SPECT/CT) using an energy window of $140 \pm 10.5 \mathrm{keV}$ and $128 \times$ 128 acquisition matrix with 60 frames (angular step $3^{\circ}$ ) at a rate of $35 \mathrm{~s}$ per frame. Attenuation correction was achieved through the CT acquisition ( $130 \mathrm{kV}, 25 \mathrm{mAs}$, B30 kernel, and 5-mm slices). Reconstruction of the images was achieved using Siemens Flash 3D, which is a proprietary iterative method of ordered-subset expectation maximization using 5 iterations and 8 subsets. Reconstructed images were fused and analyzed with Syngo TrueD (Siemens AG).

\section{Image Interpretation and Categorization}

The reference standard for hepaticoenteric arterial anatomy was the mapping angiogram and associated report that was generated by 6 experienced interventional radiologists. All scintigraphic images were reviewed for hepatic and extrahepatic ${ }^{99 \mathrm{~m}} \mathrm{Tc}-\mathrm{MAA}$ deposition by 3 experienced nuclear medicine physicians using a Syngo workstation (VE25A; Siemens Healthcare). Images were read in the following order: planar, SPECT, and SPECT/CT.

For this review of ${ }^{99 m}$ Tc-MAA distribution after hepatic arterial administration, cases were divided into 3 categories as hepatic distributions, extrahepatic distributions, and normal distribution variants (defined as findings expected due to delabeled $\left.{ }^{99 \mathrm{~m}} \mathrm{Tc}-\mathrm{MAA}\right)$. Results from NMI were also compared with expected distributions from the mapping angiograms. Statistical comparisons and significances were achieved through the Student paired $t$ test.

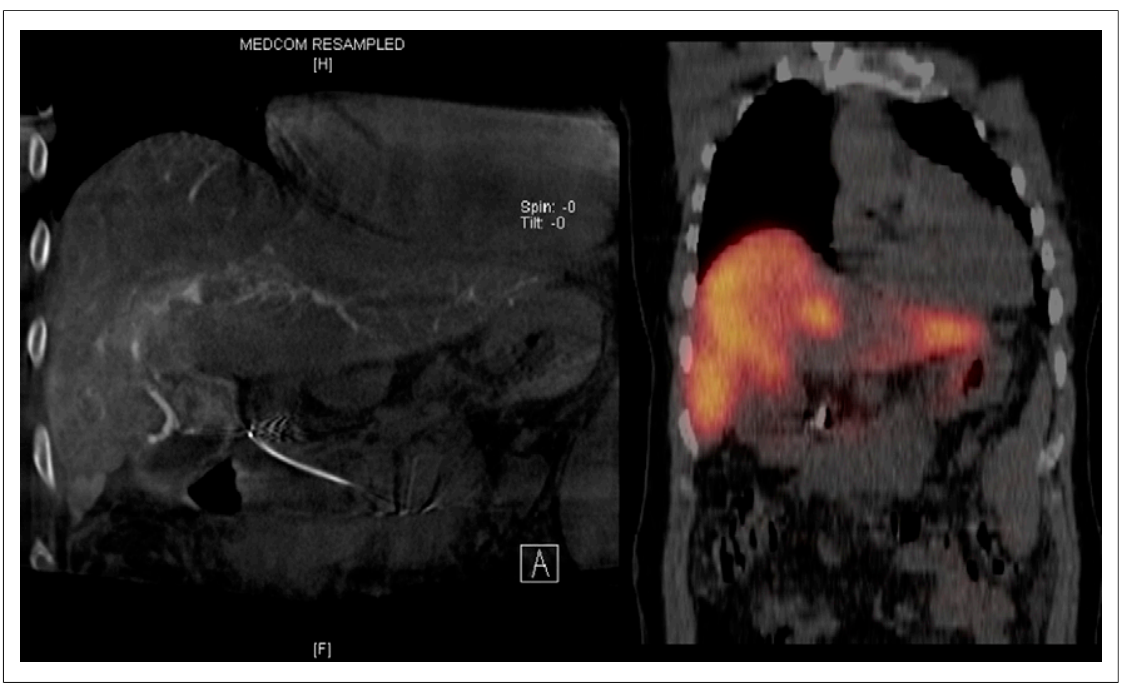

FIGURE 1. A 56-y-old man with hepatitis $C$ virus and unresectable HCC and PVT was admin-

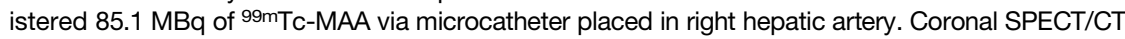
image and flat-panel CBCT demonstrate right to left hepatic shunt most likely as a result of portal vein tumor invasion.

\section{RESULTS}

\section{Patient Sample and Diagnostic Arterial Imaging}

All patients successfully underwent planning angiography with the administration of $131 \pm 38 \mathrm{MBq}$ (ranging from 63 to $178 \mathrm{MBq}$ ) of ${ }^{99 m}$ Tc-MAA and, within $2 \mathrm{~h}$, underwent successful planar imaging of the thorax and abdomen followed by SPECT/CT imaging. There were no reportable or recordable medical events.

\section{Category 1: Hepatic Distributions}

Distribution of $99 \mathrm{mTc}-\mathrm{MAA}$ within the liver depends on the microcatheter placement within the hepatic artery and the arterial supply to the tumor and normal hepatic tissue. Three major patterns of tumor perfusion were observed with ${ }^{99 m} \mathrm{Tc}-\mathrm{MAA}$ SPECT/CT images: increased uptake of ${ }^{99 m}$ Tc-MAA in the center of tumor, decreased central radiotracer uptake within the tumor, and mixed/diffuse radiotracer uptake within the liver (Supplemental Figs. 1-3; supplemental materials are available at http://jnm.snmjournals.org).

The distribution of catheter placement included 1 whole liver, 158 lobar, and 15 segmental. Most ${ }^{99 m}$ Tc-MAA administrations were with the microcatheter within the right or left hepatic artery, supplying 1 lobe of the liver. The right lobe or a segment within the right lobe was found to be perfused in 128 cases. Of the 128 right hepatic artery administrations, a subset of 51 cases involving the microcatheter positioned proximal to the right hepatic artery branch was examined for caudate lobe distributions. Within this subset, 19 cases $(37 \%)$ demonstrated activity within the caudate lobe, which was consistent with the known position of the microcatheter to the caudate artery (Supplemental Fig. 3).

Of the 174 cases, 15 cases involved administration of ${ }^{99 m}$ Tc-MAA through a microcatheter placed in a segmental branch off either the right or the left hepatic artery. For the purpose of this study, placement through a separate middle hepatic artery was considered to be a segmental administration (Supplemental Fig. 4).

Portal vein thrombosis (PVT) is thought to contribute to some of the cases involving lobe-to-lobe shunting. However, of the 8 patients with PVT, intrahepatic communications were demonstrated only on 5 (all HCC) nuclear medicine images and 4 mapping angiograms (Fig. 1).

Twenty-two of the 174 cases involved SPECT/CT imaging of patients who had received previous hepatic treatments including radiofrequency ablation, transarterial chemoembolization, radioembolization, or hepatic resections.

\section{Category 2: \\ Extrahepatic Distributions}

All cases showed some level of deposition of ${ }^{99 m}$ Tc-MAA to the lungs. The mean percentage of activity shunted from the liver to the lungs was $7.71 \% \pm 7.74 \%$ (range, $0.70 \%-57.40 \%$ ). For the patients with HCC, the mean percentage of activity shunted from the liver to the lungs was $9.37 \% \pm 9.62 \%$ (range, $0.80 \%-57.40 \%$ ). For the patients with primary disease metastatic to the liver, the mean percentage of activity shunted from the liver to the lungs was $6.20 \% \pm 5.13 \%$ (range, $0.70 \%-30.70 \%$ ). 


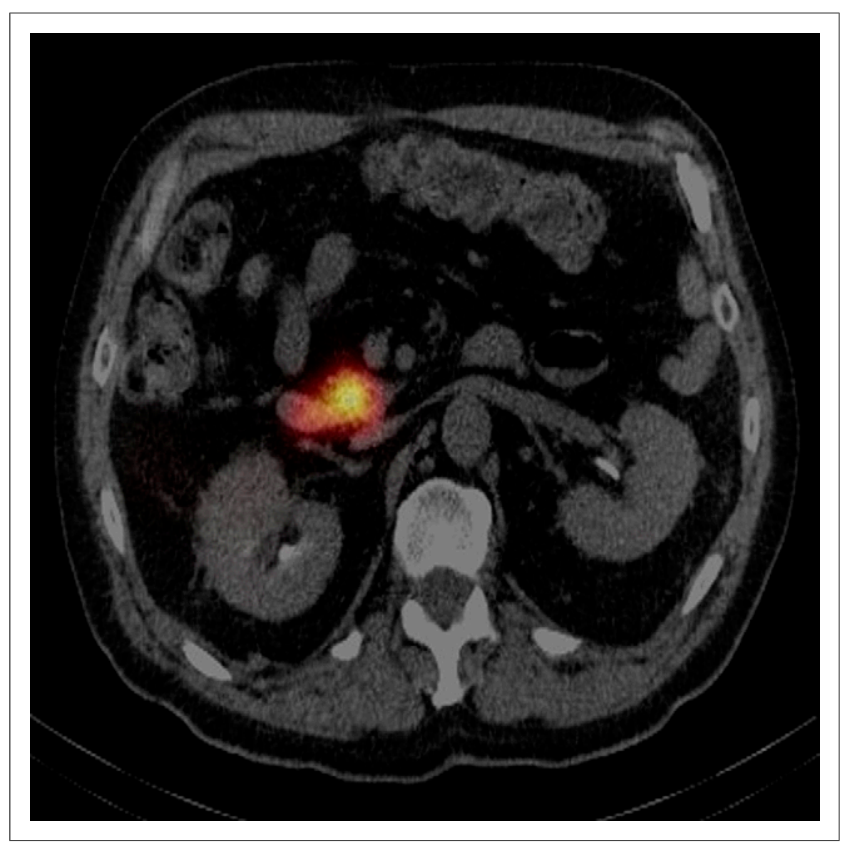

FIGURE 2. A 63-y-old man with colon carcinoma metastatic to liver was administered $85.1 \mathrm{MBq}$ of 99mTc-MAA through catheter placed in right hepatic artery proximal to gastroduodenal artery; $75 \mathrm{~min}$ after administration, SPECT/CT study was performed. Transaxial slice from reconstructed SPECT/CT image showed activity in second portion of duodenum.

For 1 case, ${ }^{99 m}$ Tc-MAA began to significantly break down into free technetium and varied-sized particles within 75 min after the administration of ${ }^{99 \mathrm{~m}}$ Tc-MAA. Because of this accelerated breakdown of the radiopharmaceutical, the pulmonary shunt calculation may be artificially elevated. The concentration of the breakdown of the radiopharmaceutical is best illustrated as the image intensity within the bladder exceeding that within the lungs.

Twenty-one of the 174 cases reviewed had hepaticoenteric arterial communications. Eight of these cases involved the purposeful placement of the microcatheter into an artery supplying extrahepatic

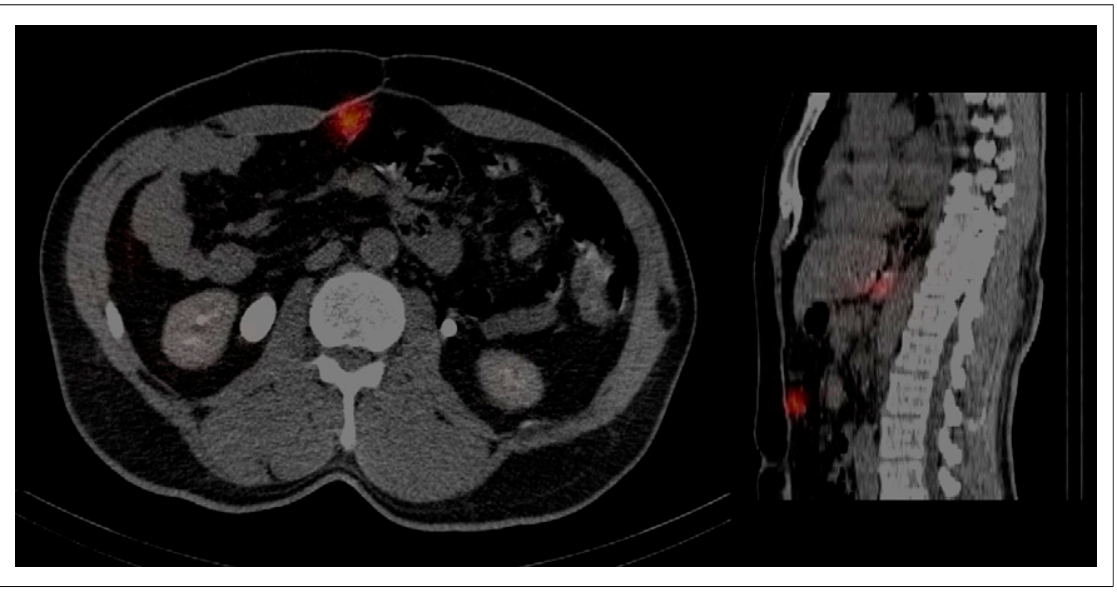

FIGURE 3. A 58-y-old man with history of metastatic neuroendocrine disease with hepatic

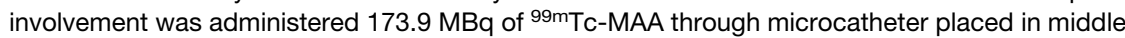
hepatic artery. Transaxial and sagittal reconstructed SPECT/CT image shows ${ }^{99 \mathrm{~m} T c-M A A}$ uptake within anterior abdominal wall due to flow from falciform artery, which originated from middle hepatic artery. tissue (1 falciform artery, 2 gastroduodenal arteries, and 5 gastric arteries). Duodenal uptake was from ${ }^{99 \mathrm{~m}}$ Tc-MAA administration through a catheter placed in the right hepatic artery but proximal to the gastroduodenal artery (Fig. 2). ${ }^{99 \mathrm{~m} T c-M A A}$ uptake within the anterior abdominal wall was due to $99 \mathrm{~m}$ Tc-MAA administration through a microcatheter placed within the middle hepatic artery with the falciform artery arising off the middle hepatic artery (Fig. 3). Focal activity corresponding to the medial left lobe hepatoma and focal activity within the medial wall of the proximal stomach were due to a replaced left gastric artery (Fig. 4).

For treatment, distribution to the gallbladder can often be avoided by placing the microcatheter distal to the cystic artery. However, there are cases in which the gallbladder will receive a radiation dose because the microcatheter can be placed only proximal to the cystic artery. Reviewing the images in a subset of 51 cases involving patients with gallbladders still present showed 25 cases involving ${ }^{99} \mathrm{~m}$ Tc-MAA distribution to the gallbladder wall. Treatment was still performed on patients when the microcatheter could be placed distally as well as on patients in whom the microcatheter required proximal placement.

\section{Category 3: Normal Distribution Variants}

In vivo formation of free pertechnetate was considered part of the standard distribution when the ${ }^{99 m}$ Tc-MAA imaging demonstrated activity within the lumen of the stomach along with activity in either the thyroid or the salivary glands or both (Fig. 5). Fragmented ${ }^{99 \mathrm{~m}}$ Tc-MAA was also considered a normal distribution variant when the imaging indicated activity within the kidneys and the lumen of the stomach. In reviewing all $174{ }^{99 m} \mathrm{Tc}-\mathrm{MAA}$ image case reports, we found that 66 of the 174 cases showed indication of free pertechnetate or fragmented ${ }^{99 \mathrm{~m}} \mathrm{Tc}-\mathrm{MAA}$.

Alternative findings included both radioactive distributions that were not related to arterial distribution of $99 \mathrm{~m}$ Tc-MAA and anatomic notations based on the low-dose CT image used for attenuation correction. Two examples included ${ }^{99 \mathrm{~m}} \mathrm{Tc}$-pertechnetate distribution to the thyroid, in which imaging showed hyperactivity within the thyroid nodule (Fig. 5) and focal uptake of ${ }^{99 \mathrm{~m} T c-l a b e l e d}$ fragmented MAA or ${ }^{99 \mathrm{~m}}$ Tc-pertechnetate within the renal poles that was different from the homogeneous distribution observed within the kidneys related to physiologic breakdown of ${ }^{99 \mathrm{~m} T c-M A A . ~ G a l l s t o n e s ~}$ within the gallbladder will sometimes create a density artifact on the attenuationcorrection map. As a result of the density artifact, a focal area of the gallbladder wall may appear to receive a higher concentration of ${ }^{99 m}$ Tc-MAA activity, but this is artifactual. Five of the 174 cases reviewed showed alternative findings.

\section{DISCUSSION}

Radioembolization has evolved for the palliative treatment of patients with primary and secondary malignancies. The safety of this therapy requires detailed planning angiography with ${ }^{99 \mathrm{~m}} \mathrm{Tc}-\mathrm{MAA}$ administration. A detailed discussion of considerations of normal hepatic perfusion and hepaticoenteric arterial anatomy in the context of radioembolization has been published elsewhere 


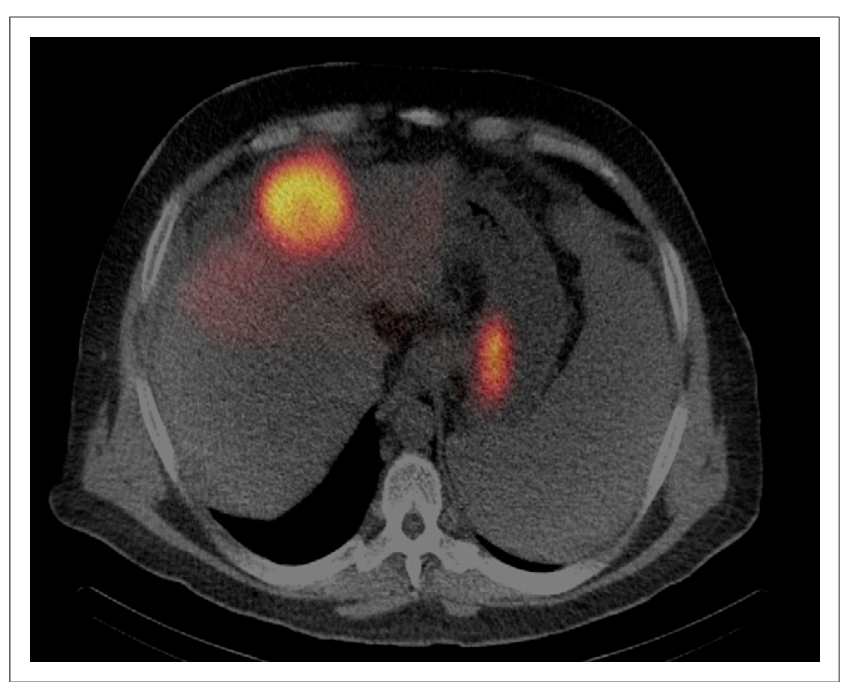

FIGURE 4. A 76-y-old woman with history of hepatitis $C$ infection and suspected HCC was administered $81.4 \mathrm{MBq}$ of ${ }^{99 \mathrm{~m} T \mathrm{Tc}-\mathrm{MAA} \text { through }}$ catheter placed in middle hepatic artery and replaced left gastric artery. SPECT/CT images were subsequently obtained. Transaxial reconstructed SPECT/CT fused image of medial left hepatic lobe, stomach, and spleen shows focal activity corresponding with left lobe hepatoma and shows focal activity in medial wall of proximal stomach, indicating significant abnormal shunting of liver activity.

$(10,12-16)$. This study reports our experience in treatment planning for 174 patients. We reviewed the imaging findings after intrahepatic ${ }^{99 \mathrm{~m} T c-M A A}$ administration and reported the incidence of normal variants and extrahepatic deposition from both NMI and planning angiography (Table 1).

Regardless of location within the liver, greater uptake of ${ }^{99 m}$ Tc-MAA is expected in regions of the tumor given that tumor beds are predominantly supplied via the arterial system of the liver whereas normal hepatic parenchyma is supplied by the portal system. Three major patterns of tumor perfusion are observed with 99mTc-MAA SPECT/CT images (Supplemental Figs. 1-3). A detailed discussion of considerations of normal hepatic perfusion and

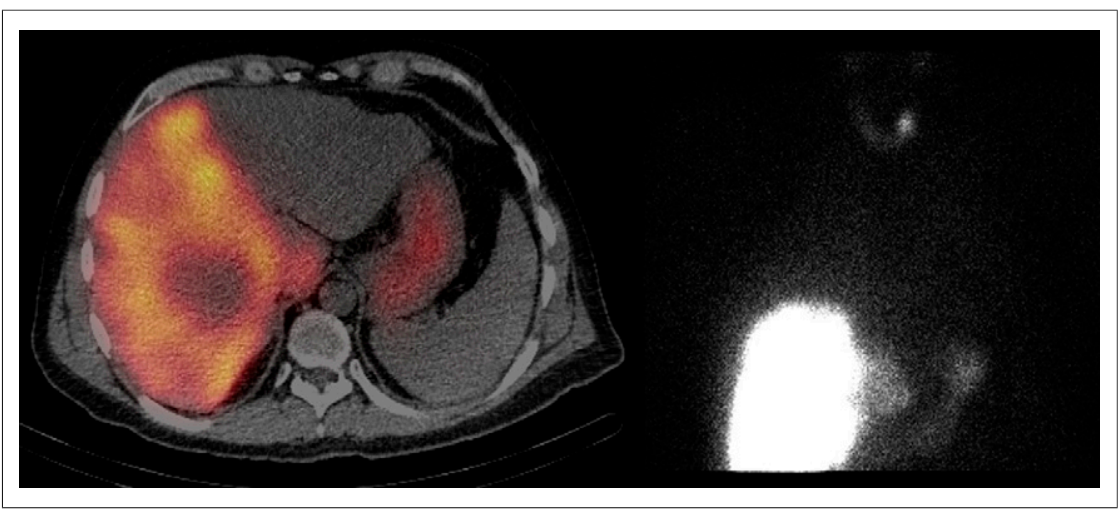

FIGURE 5. A 45-y-old man with metastatic adenocarcinoma of gastroesophageal junction with hepatic involvement was administered $155.4 \mathrm{MBq}$ of 99mTc-MAA through catheter placed in right hepatic artery; after administration, SPECT/CT study was performed. Transaxial slice from reconstructed SPECT/CT image of abdomen reveals that both right hepatic and caudate lobes were perfused with inhomogeneous distribution of activity corresponding to patient's multifocal intrahepatic lesions. In addition, free ${ }^{99 \mathrm{~m} T c-p e r t e c h n e t a t e}$ can be observed in lumen of stomach. Incidentally noted is focal area of increased uptake in region of left upper pole of thyroid gland. hepaticoenteric arterial anatomy in the context of radioembolization has been published elsewhere $(10,12-16)$. In a recent publication by Ilhan et al., SPECT/CT images were reviewed for tumor uptake distribution and graded on the basis of the concentration of ${ }^{99 m}$ Tc-MAA and distribution within the tumor (17). Most lesions were of grade 1 (high uptake, homogeneous distribution) or grade 2 (high uptake, heterogeneous distribution). Patients with grade 1 or 2 also demonstrated better tumor response. Along these lines, several authors proposed a more quantitative method using 99mTc-MAA SPECT/CT to determine a threshold dose for treatment with ${ }^{90}$ Y-microspheres $(14,18-20)$.

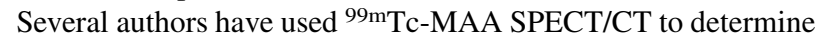
a threshold dose for treatment with ${ }^{90}$ Y-microspheres. For glass microspheres, Garin et al. reported that a tumor dose exceeding 205 Gy and Chiesa et al. reported that a tumor dose of $257 \mathrm{~Gy}$ were required to induce tumor response $(21,22)$. Similarly, Riaz et al. reported that when segmental dosimetry (segment receives $100 \%$ of radiation dose) was used, a dose greater than 190 Gy was required to perform a segmentectomy (Supplemental Fig. 4) (23).

For patients being treated for HCC with PVT, SPECT/CT plays an important role for performing more tumor-based treatment planning dosimetry. In these patients, PET/CT demonstrated that microspheres distributed within the PVT (24). Overall survival of these patients improved using the boosted personalized dose method described by Garin et al. in which the tumor dose of $205 \mathrm{~Gy}$ was achieved through increasing the lobar dose to a 150-Gy maximum (25). From our study, the perfused volume would include both the right and the left lobar volumes for $62.5 \%$ of the patients with HCC and PVT. Therefore, a little less than half this population would be underdosed using the standard lobar dose of $120 \mathrm{~Gy}$.

Another potential concern for performing personalized dosimetry based on SPECT/CT may be gallbladder uptake of microspheres that would result in radiation-induced cholecystitis. Our study showed that for patients with a gallbladder present the ${ }^{99 m}$ Tc-MAA would be taken up by $49 \%$ of the patients when the microcatheter was placed proximally to the cystic artery. However, by adjusting the position of the microcatheter, the percentage of patients with gallbladder uptake could be reduced to $16 \%$. Our result is similar to a published SPECT/CT study, in which the repositioning of the microcatheter resulted in a reduction of gallbladder visibility in $90 \%$ of the cases (26).

The question still remains as to whether we need to take actions such as coiling the cystic artery or surgically removing the gallbladder to prevent radiationinduced cholecystitis. In a study performed at our institution, we saw only 2 cases $(0.6 \%)$ of radiation-induced cholecystitis, which is similar to other published results $(27,28)$. None of the patients in this study developed cholecystitis despite showing $99 \mathrm{~m}$ Tc-MAA uptake within the gallbladder.

If arteriovenous shunting into branches of the hepatic vein is present, then ${ }^{90} \mathrm{Y}$ microspheres can reach the pulmonary circulation, producing unwanted pulmonary toxicity. NMI from this study showed 
TABLE 1

Imaging Results from This Study and Results from Other Published Data

\begin{tabular}{|c|c|c|c|c|c|}
\hline Category & Subcategory & This study & $\begin{array}{l}\text { Lenoir } \\
\text { et al. (13) }\end{array}$ & $\begin{array}{l}\text { Ahmadzadehfar } \\
\text { et al. (15) }\end{array}$ & $\begin{array}{l}\text { Hamami } \\
\text { et al. (16) }\end{array}$ \\
\hline \multirow{5}{*}{$\begin{array}{l}\text { Hepatic } \\
\text { distributions }\end{array}$} & Number of SPECT/CT & 174 & 139 & 90 & 68 \\
\hline & $\begin{array}{l}\text { NMI intrahepatic lobe } \\
\text { distributions due to } \\
\text { PVT (overall NMI) }\end{array}$ & $62.5 \%(2.9 \%)$ & $\begin{array}{l}31 \% \\
(7 \%)\end{array}$ & NR & NR $(4 \%)$ \\
\hline & $\begin{array}{l}\text { Angiogram intrahepatic lobe } \\
\text { distributions due to PVT } \\
\text { (overall and angiograms) }\end{array}$ & $57.1 \%(2.3 \%)$ & NR & NR & NR \\
\hline & $\begin{array}{l}\text { Prior radiofrequency ablation } \\
\text { or embolizations }\end{array}$ & $13 \%$ & NR & NR & NR \\
\hline & $\begin{array}{l}\text { Distribution to the caudate lobe } \\
\text { from right hepatic artery } \\
\text { administrations }\end{array}$ & $37 \%(19 / 51)$ & NR & NR & NR \\
\hline \multirow[t]{3}{*}{$\begin{array}{l}\text { Extrahepatic } \\
\text { distributions }\end{array}$} & $\begin{array}{l}\text { Distributions from hepaticoenteric } \\
\text { arterial communications as } \\
\text { demonstrated on SPECT/CT }\end{array}$ & $5 \%$ & $9 \%$ & $38 \%$ & $24 \%$ \\
\hline & $\begin{array}{l}\text { Distributions from hepaticoenteric } \\
\text { arterial communications as } \\
\text { demonstrated on angiograms, } \\
\text { DSA or CBCT with contrast }\end{array}$ & $16 \%$ & NR & $34 \%$ & $28 \%$ \\
\hline & Gallbladder visualization & $49 \%$ & $12 \%$ & $12 \%$ & $9 \%$ \\
\hline \multirow[t]{2}{*}{$\begin{array}{l}\text { Normal distribution } \\
\text { variant }\end{array}$} & $\begin{array}{l}\text { Images indicating free } \\
\text { pertechnetate or delabeled } \\
\text { MAA }\end{array}$ & $38 \%$ & $22 \%$ & $4 \%$ & NR \\
\hline & $\begin{array}{l}\text { Thyroid nodule, renal poles, } \\
\text { reconstruction/metallic artifacts }\end{array}$ & $3 \%$ & NR & NR & NR \\
\hline
\end{tabular}

${ }^{99 m}$ Tc-MAA distribution to the lungs from all of the patients. One possible reason for this discrepancy is that the package insert indicates that up to $1 \%-2 \%$ of these particles may be less than 15 $\mu \mathrm{m}$. The smaller particle diameter $(<8 \mu \mathrm{m})$ facilitates movement into the lungs through normal vasculature rather than through malignant arteriovenous communications, consequently leading to greater activity detected within the lungs. Another possible reason could be due to the timing among the ${ }^{99 m}$ Tc-MAA production, the ${ }^{99 \mathrm{~m}} \mathrm{Tc}-\mathrm{MAA}$ infusion, and the NMI. The useful life of the particles is approximately $6 \mathrm{~h}$. As a result, longer delays could result in artificially elevated lung shunt values (29).

Arteriovenous shunting is well known to exist in HCC (30). It has also been suggested that higher percentages of lung shunting are seen with HCC than with metastatic disease to the liver (30). Although the range of percentages of lung shunting are comparable between patients with HCC and patients with metastatic disease to the liver, the mean values from this cohort are statistically different $(P=0.004)$.

Focal increase in ${ }^{99 m}$ Tc-MAA activity within the falciform artery, phrenic artery, duodenum, gastric lumen, or anywhere along the gastrointestinal tract is concerning for extrahepatic shunting due to hepaticoenteric arterial communications (15). These vessels include the falciform, accessory or left phrenic, right, or accessory gastric arteries (from the left hepatic artery), supraduodenal, retroduodenal, and accessory right hepatic ar- tery feeding segment 6 (from the gastroduodenal artery). When the angiogram technique outlined in Lewandowski et al. was used, none of our ${ }^{99 \mathrm{~m} T c-M A A ~ S P E C T / C T}$ images showed extrahepatic uptake due to hepaticoenteric arterial communications that was not also observed in the planning angiogram or flat-panel cone-beam CT (CBCT) $(10,12)$. To illustrate the uptake of ${ }^{99 m}$ Tc-MAA due to these arterial distributions, 8 patients were purposefully administered the radiopharmaceutical proximal to the uncoiled vessel. Before treatment with microspheres, either the vessel was coiled or the microcatheter was placed distally.

When comparing CBCT versus ${ }^{99 m}$ Tc-MAA scintigraphy, Louie et al. showed that CBCT demonstrated 19\% extrahepatic enhancements that were not evident on MAA imaging (31). Similarly, our study showed that with digital subtraction angiography and CBCT angiography can predict $99.5 \%$ of the hepatic and extrahepatic distribution.

\section{CONCLUSION}

Patients being considered for radioembolization should undergo angiographic and scintigraphic assessment with ${ }^{99 \mathrm{~m}} \mathrm{Tc}-\mathrm{MAA}$ using planar and tomography imaging for the assessment of hepaticoenteric arterial communications, hepatopulmonary shunting, and appropriate dosimetry considerations. A thorough review of 
the NMI findings is essential to ensure proper catheter positioning to optimize treatment outcomes.

\section{DISCLOSURE}

The costs of publication of this article were defrayed in part by the payment of page charges. Therefore, and solely to indicate this fact, this article is hereby marked "advertisement" in accordance with 18 USC section 1734. Robert J. Lewandowski and Riad Salem are advisors to BTG. No other potential conflict of interest relevant to this article was reported.

\section{REFERENCES}

1. Leung WT, Lau WY, Ho SK, et al. Measuring lung shunting in hepatocellular carcinoma with intrahepatic-arterial technetium-99m macroaggregated albumin. J Nucl Med. 1994;35:70-73.

2. Leung TW, Lau WY, Ho SK, et al. Radiation pneumonitis after selective internal radiation treatment with intraarterial 90yttrium-microspheres for inoperable hepatic tumors. Int J Radiat Oncol Biol Phys. 1995;33:919924.

3. Andrews JCWS, Ackermann RJ, Cotton LA, Ensminger WD, Shapiro B. Hepatic radioembolization with yttrium-90 containing glass microspheres: preliminary results and clinical follow-up. J Nucl Med. 1994;35:1637-1644.

4. Wollner I, Knutsen C, Smith P, et al. Effects of hepatic arterial yttrium 90 glass microspheres in dogs. Cancer. 1988;61:1336-1344.

5. Herba MJ, Illescas FF, Thirlwell MP, et al. Hepatic malignancies: improved treatment with intraarterial Y-90. Radiology. 1988;169:311-314.

6. Shepherd FA, Rotstein LE, Houle S, Yip TC, Paul K, Sniderman KW. A phase I dose escalation trial of yttrium-90 microspheres in the treatment of primary hepatocellular carcinoma. Cancer. 1992;70:2250-2254.

7. Houle S, Yip TK, Shepherd FA, et al. Hepatocellular carcinoma: pilot trial of treatment with Y-90 microspheres. Radiology. 1989;172:857-860.

8. Dancey JE, Shepherd FA, Paul K, et al. Treatment of nonresectable hepatocellular carcinoma with intrahepatic ${ }^{90}$ Y-microspheres. J Nucl Med. 2000;41:16731681.

9. Denecke T, Ruhl R, Hildebrandt B, et al. Planning transarterial radioembolization of colorectal liver metastases with yttrium 90 microspheres: evaluation of a sequential diagnostic approach using radiologic and nuclear medicine imaging techniques. Eur Radiol. 2008;18:892-902.

10. Lewandowski RJ, Sato KT, Atassi B, et al. Radioembolization with ${ }^{90} \mathrm{Y}$ microspheres: angiographic and technical considerations. Cardiovasc Intervent Radiol. 2007;30:571-592.

11. Salem R, Thurston KG. Radioembolization with 90yttrium microspheres: a state-of-the-art brachytherapy treatment for primary and secondary liver malignancies-part 1: technical and methodologic considerations. J Vasc Interv Radiol. 2006;17:1251-1278.

12. Liu DM, Salem R, Bui JT, et al. Angiographic considerations in patients undergoing liver-directed therapy. J Vasc Interv Radiol. 2005;16:911-935.

13. Lenoir L, Edeline J, Rolland Y, et al. Usefulness and pitfalls of MAA SPECT/CT in identifying digestive extrahepatic uptake when planning liver radioembolization. Eur J Nucl Med Mol Imaging. 2012;39:872-880.

14. Ahmadzadehfar H, Duan H, Haug AR, Walrand S, Hoffmann M. The role of SPECT/CT in radioembolization of liver tumours. Eur J Nucl Med Mol Imaging. 2014;41(suppl 1):S115-S124.
15. Ahmadzadehfar H, Sabet A, Biermann K, et al. The significance of ${ }^{99 m}$ Tc-MAA SPECT/CT liver perfusion imaging in treatment planning for ${ }^{90} \mathrm{Y}$-microsphere selective internal radiation treatment. J Nucl Med. 2010;51:1206-1212.

16. Hamami ME, Poeppel TD, Muller S, et al. SPECT/CT with ${ }^{99 m}$ Tc-MAA in radioembolization with ${ }^{90} \mathrm{Y}$ microspheres in patients with hepatocellular cancer. J Nucl Med. 2009;50:688-692.

17. Ilhan H, Goritschan A, Paprottka P, et al. Systematic evaluation of tumoral ${ }^{99 m}$ Tc-MAA uptake using SPECT and SPECT/CT in 502 patients before ${ }^{90} \mathrm{Y}$ radioembolization. J Nucl Med. 2015;56:333-338.

18. Chiesa C, Lambert B, Maccauro M, et al. Pretreatment dosimetry in HCC radioembolization with ${ }^{90} \mathrm{Y}$ glass microspheres cannot be invalidated with a bare visual evaluation of ${ }^{99 m}$ Tc-MAA uptake of colorectal metastases treated with resin microspheres. J Nucl Med. 2014;55:1215-1216.

19. Chiesa C, Maccauro M, Romito R, et al. Need, feasibility and convenience of dosimetric treatment planning in liver selective internal radiation therapy with ${ }^{90} \mathrm{Y}$ microspheres: the experience of the National Tumor Institute of Milan. $Q J$ Nucl Med Mol Imaging. 2011;55:168-197.

20. Garin E, Lenoir L, Rolland Y, et al. Dosimetry based on ${ }^{99 \mathrm{~m}} \mathrm{Tc}$-macroaggregated albumin SPECT/CT accurately predicts tumor response and survival in hepatocellular carcinoma patients treated with ${ }^{90}$ Y-loaded glass microspheres: preliminary results. $J$ Nucl Med. 2012;53:255-263.

21. Garin E, Lenoir L, Edeline J, et al. Boosted selective internal radiation therapy with Y-loaded glass microspheres (B-SIRT) for hepatocellular carcinoma patients: a new personalized promising concept. Eur J Nucl Med Mol Imaging. 2013;40:1057-1068.

22. Chiesa C, Mira M, Maccauro M, et al. A dosimetric treatment planning strategy in radioembolization of hepatocarcinoma with ${ }^{90} \mathrm{Y}$ glass microspheres. $Q \mathrm{~J} \mathrm{Nucl}$ Med Mol Imaging. 2012;56:503-508.

23. Riaz A, Gates VL, Atassi B, et al. Radiation segmentectomy: a novel approach to increase safety and efficacy of radioembolization. Int J Radiat Oncol Biol Phys. 2011;79:163-171.

24. Padia SA, Alessio A, Kwan SW, Lewis DH, Vaidya S, Minoshima S. Comparison of positron emission tomography and bremsstrahlung imaging to detect particle distribution in patients undergoing yttrium-90 radioembolization for large hepatocellular carcinomas or associated portal vein thrombosis. J Vasc Interv Radiol. 2013;24:1147-1153.

25. Garin E, Rolland Y, Edeline J, et al. Personalized dosimetry with intensification using ${ }^{90}$ Y-loaded glass microsphere radioembolization induces prolonged overall survival in hepatocellular carcinoma patients with portal vein thrombosis. $\mathrm{J} \mathrm{Nucl}$ Med. 2015;56:339-346.

26. Prince JF, van den Hoven AF, van den Bosch MA, Elschot M, de Jong HW, Lam MG. Radiation-induced cholecystitis after hepatic radioembolization: do we need to take precautionary measures? J Vasc Interv Radiol. 2014;25:1717-1723.

27. Sag AA, Savin MA, Lal NR, Mehta RR. Yttrium- 90 radioembolization of malignant tumors of the liver: gallbladder effects. AJR. 2014;202:1130-1135.

28. Atassi B, Bangash AK, Lewandowski RJ, et al. Biliary sequelae following radioembolization with Yttrium-90 microspheres. J Vasc Interv Radiol. 2008;19:691-697.

29. De Gersem R, Maleux G, Vanbilloen H, et al. Influence of time delay on the estimated lung shunt fraction on ${ }^{99 \mathrm{~m}} \mathrm{Tc}$-labeled MAA scintigraphy for ${ }^{90} \mathrm{Y}$ microsphere treatment planning. Clin Nucl Med. 2013;38:940-942.

30. Ho S, Lau WY, Leung WT, et al. Arteriovenous shunts in patients with hepatic tumors. J Nucl Med. 1997;38:1201-1205.

31. Louie JD, Kothary N, Kuo WT, et al. Incorporating cone-beam CT into the treatment planning for yttrium-90 radioembolization. J Vasc Interv Radiol. 2009;20:606-613. 